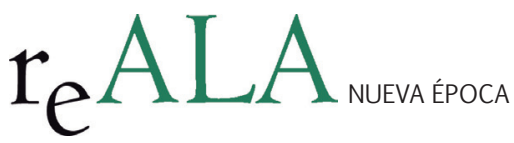

REALA, n 1, enero-junio 2014, ISSN: 1989-8975

DOI: http://dx.doi.org/10.24965/reala.voi1.10141

\title{
Control judicial de la reforma laboral aplicada a las Administraciones Públicas
}

\author{
Francisco José Rodríguez Márquez \\ Excmo. Ayuntamiento de Estepona \\ fcojoserodriguez65@gmail.com \\ Recibido: 21 de agosto de 2013 \\ Aceptado: 7 de noviembre de 2013
}

\begin{abstract}
Resumen
La reciente reforma del mercado laboral abordada por el actual gobierno han supuesto, también en la Administración Pública, modificaciones de gran calado en el sistema de relaciones laborales, con especial incidencia en el personal con relación de carácter laboral. Con este trabajo pretendemos hacer un seguimiento de las sentencias que, en distintas instancias, han recaído desde la entrada en vigor de la misma, con especial atención a los expedientes de despido colectivo y a las denominadas "cláusulas de descuelgue" de los convenios colectivos.
\end{abstract}

Palabras clave

Reforma laboral, sentencias, Administración Pública

\section{Judicial Control of the Labor Reform applied to the Public Administrations}

\section{Abstract}

The recent job market reform implemented by the present government entails -for the public administration as well-major modifications in the work relationship system, especially relevant for the non-civil servant public administrations employees. By carrying out this project we intend to do a follow-up of the different sentences which, in every level of judicial review, have befallen ever since the implementation of such reform; we will pay special attention to those collective redundancy plans, as well as to the so-called opt-out clauses of the collective agreements.

\section{Keywords}

Job market reform, Judicial Judgement, Public Administration 


\section{CÓMO HA AFECTADO LA CRISIS ECONÓMICA AL EMPLEO PÚBLICO}

El 14 de septiembre de 2008 , la noticia de portada de la prensa mundial era la presentación, por parte de la aseguradora estadounidense Lehman Brothers, de la mayor bancarrota de la historia, con un pasivo de 430.000 millones $€$, que afectaba a más de 100.000 entidades, fondos de inversión y fondos de pensiones. Esa quiebra, cifrada en seis veces superior a la de Worldcom en 2002 y 10 veces mayor que la de Enron en 2001, convirtió el 14 de septiembre en el día en el que el sistema bancario de Estados Unidos cambió su forma de funcionar, según la crónica de El País de 16/09/2008. Sin apenas solución de continuidad, una crisis financiera se convirtió en una crisis económica y esta crisis económica ha derivado en una recesión de escala mundial.

Desde entonces, las sociedades europeas han asistido a un recorte brutal de derechos democráticos, se han producido cambios de gobierno impensables, grupos de tecnócratas se han puesto al frente de países sin pasar por las urnas, un país miembro de la Unión Europea como Grecia ha visto cómo la troika' le imponía como primer ministro a un ex-consejero de Goldman Sachs, etc.

Una de las recetas que se han ido aplicando con mayor intensidad como consecuencia de esta crisis es la de la austeridad. Ello nos lleva al sector público sobre el que, generalizando que es gerundio, parece existir cierto nivel de consenso en admitir que las plantillas de personal de las Administraciones Públicas están sobredimensionadas. A estar de acuerdo o no con dicha afirmación nos puede ayudar esta tabla en la que se muestra la evolución del empleo público entre 2005 y $2012^{2}$.

TABLA 1

\begin{tabular}{|c|c|c|c|c|c|c|c|c|}
\hline \multicolumn{9}{|c|}{ Encuesta de Población Activa } \\
\hline \multicolumn{9}{|c|}{ Ocupados } \\
\hline \multicolumn{9}{|c|}{$\begin{array}{l}\text { Asalariados del sector público por tipo de administración, sexo y grupo de edad } \\
\text { Unidades:Miles de personas }\end{array}$} \\
\hline & 2005 & 2006 & 2007 & 2008 & 2009 & 2010 & 2011 & 2012 \\
\hline \multicolumn{9}{|l|}{ Ambos sexos } \\
\hline \multicolumn{9}{|l|}{ Total } \\
\hline Total & $2.864,2^{\top}$ & $2.882,2 \bigvee$ & $2.913,0^{\top}$ & $2.958,6^{\top}$ & $3.062,0^{\backslash}$ & $3.129,6^{\top}$ & $3.190,0^{\top}$ & $3.013,6^{\top}$ \\
\hline Central & $512,3^{\top}$ & $474,3^{\top}$ & $511,9^{\top}$ & $521,4^{\top}$ & 526,6 ไ & $536,7^{\top}$ & $547,9^{\mathbf{V}}$ & $528,9^{\top}$ \\
\hline Seguridad Social & $365,0^{\top}$ & $352,1^{\top}$ & $57,0^{\top}$ & $45,5^{\top}$ & 38,8 & $38,3^{\top}$ & $39,0^{\top}$ & $39,1^{\top}$ \\
\hline Comunidad Autónoma & $1.194,4^{\top}$ & $1.231,3^{\mathbf{V}}$ & $1.536,7^{\top}$ & $1.600,7^{\top}$ & $1.674,7^{\top}$ & $1.744,5^{\top}$ & $1.784,0^{\top}$ & $1.693,6^{\top}$ \\
\hline Local & 608,8 & $623,7^{\top}$ & $630,0^{\top}$ & $631,6^{\mathbf{V}}$ & $663,1^{\mathbf{v}}$ & $656,6^{\top}$ & $654,9^{\boldsymbol{V}}$ & $591,4^{\top}$ \\
\hline Empresa e Institución Pública & $151,0^{\mathbf{V}}$ & $172,0^{\backslash}$ & 156,8 ' & $145,4^{\top}$ & $145,4^{\top}$ & $144,5^{\top}$ & $152,4^{\top}$ & $149,4^{\top}$ \\
\hline Otro tipo & $16,7^{\searrow}$ & 11,1 & $10,0^{\top}$ & $8,4^{\mathbf{V}}$ & $9,6^{\mathbf{V}}$ & 7,8 ' & $9,4^{\top}$ & $9,5^{\backslash}$ \\
\hline No sabe & $16,0^{\top}$ & $17,7^{\nearrow}$ & $10,6^{\mathbf{V}}$ & $5,7^{\top}$ & $3,8^{\mathbf{V}}$ & 1,1 & $2,5^{\top}$ & 1,6 \\
\hline
\end{tabular}

FUENTE: INE.

En numerosos casos se adoptaron medidas que, bajo diversas denominaciones (racionalización, optimización, redimensionamiento, ajuste de plantillas) perseguían, fundamentalmente, reducir la plantilla de personal y, en consecuencia, el peso del Capítulo I de Gastos de Personal en el Presupuesto con cataplasmas incluidas alguna del calibre del Real Decreto Ley 8/2010... No obstante, hasta 2012 no se observa tendencia a la baja en cuanto al número de empleados públicos.

Y mientras todo esto ocurría, ¿qué pasaba en las entidades locales, en los Ayuntamientos y Diputaciones, que venían de un ciclo ciertamente expansivo, especialmente en materia de empleo público? Pues que, corregida y aumentada esta sensación de sobredimensionamiento por parte de la ciudadanía y agravada por la caída de ingresos extraordinarios derivados, fundamentalmente, de la especulación y el ladrillazo, pero sin estar en posesión de las herramientas reglamentarias adecuadas para hacer frente a dicha situación (en manos del Estado y las CC.AA.) les ha tocado hacer de sufridores de las recetas que los distintos gobiernos han considerado acertado ir aplicando. De este modo, en la tabla anterior se observa una significativa caída en el número de empleados al servicio de las EE.LL. que desciende a niveles anteriores a 2005.

1 La troika o troica está formada por el Banco Central Europeo (BCE), el Fondo Monetario Internacional (FMI) y la Comisión Europea (CE). Estos tres organismos multilaterales se dedican de manera conjunta a estudiar la situación económica de los países para señalarles qué medidas y reformas económicas deben llevar a cabo si quieren sanear sus cuentas y crecer.

2 http://www.ine.es/jaxiBD/tabla.do?per=12\&type=db\&divi=EPA\&idtab=699 
Este adelgazamiento del sector público local ha tenido una especial incidencia en los empleados con relación de carácter laboral. Y ello es así por dos razones:

1. La fuerte tasa de laboralización en las Entidades Locales que supera el $60 \%$ del total de efectivos. Ello se puede explicar tanto por su carácter de administración de proximidad, responsable de la gestión de muchos servicios públicos, como por la inclinación de los políticos locales a optar por la selección de personal laboral por diversas razones

2. La mayor parte de las medidas tendentes a conseguir un decremento del coste de los empleados públicos locales lo han sido dentro de la normativa que reforma el mercado de trabajo.

Entre otras muchas reformas de calado, la D.A. $2^{\text {a }}$ Ley 3/2012 procede a añadir una D.A. $20^{a}$ al ET en la que se prevé, entre otros aspectos, la aplicación del artículo 52.c) de dicho texto legal y sus normas de desarrollo al personal laboral al servicio de los entes, organismos y entidades que forman parte del sector público, en los términos en que éste es definido en el art. 3.1 TRLCSP. Lamentablemente, la D.A. $3^{\text {a }}$ Ley 3/2012 excluye la posibilidad de aplicar la suspensión de contratos de trabajo al personal laboral (lo que elimina la posibilidad de aplicar criterios paliativos y alternativos al despido) rompiendo, en este aspecto, su equiparación con los trabajadores de las empresas privadas y dejando como única vía para la adaptación de las plantillas del personal laboral a las condiciones presupuestarias y de los servicios a prestar la vía del despido objetivo o colectivo por causas económicas, técnicas, organizativas o de producción, todo ello conforme a lo establecido en art. 7 EBEP "El personal laboral al servicio de las Administraciones Públicas se rige, además de por la legislación laboral y por las demás normas convencionalmente aplicables, por los preceptos de este Estatuto que así lo dispongan", así como lo dispuesto en términos similares por los arts. 103 LBRL y 177 TRRL.

En otro orden de cosas, la tasa de temporalidad existente en las Administraciones constituye no sólo la evidencia del incumplimiento general del derecho de acceso al empleo público de los ciudadanos, sino también la debilidad de este tipo de personal en sus relaciones con la Administración. Así, los recortes han incidido tanto sobre el empleo temporal (pese a que la contratación de personal laboral temporal solo es legalmente posible para desempeñar los puestos de trabajo que no estén reservados a funcionarios, conforme a los arts. 9.2 y 11.2 del EBEP y la legislación de función pública en cada caso aplicable, y con los límites y requisitos que prevé el art. 15 ET), como sobre el empleo interino cuya supresión resulta relativamente sencilla para una Corporación. No debemos olvidar el impacto que ha tenido en el empleo público local las escaseces presupuestarias del Estado y las CC.AA., lo que se ha reflejado en el recorte o, incluso, la desaparición de numerosas subvenciones que llevaban aparejada la contratación de personal (si bien, con relación de carácter temporal) lo que ha tenido, como lógico correlato, la desaparición de estos puestos de trabajo.

Parece pues, interesante, conocer el criterio que están siguiendo los jueces y tribunales en relación con la aplicación del despido colectivo en las Administraciones Públicas puesto que el Preámbulo de la Ley 3/2012 deja claro que el control judicial de los despidos amparados en este tipo de causas debe ceñirse a una valoración sobre la concurrencia de unos hechos: las causas. Al suprimirse la necesidad de autorización administrativa, manteniendo la exigencia comunitaria de un período de consultas (pero sin exigirse un acuerdo con los representantes de los trabajadores para proceder a los despidos) se asimilan los despidos colectivos con el resto de despidos a efectos de su impugnación y calificación judicial, con lo que el control judicial sobre los hechos también se aplica a los despidos por causas objetivas ex art. 52 c) ET. De hecho, la función a realizar por la Inspección de Trabajo, con la actual regulación, se limita al control del cumplimiento de la buena fe y la evitación del abuso de derecho en el desarrollo del expediente, sin entrar a valorar la causa extintiva.

Recordemos que, entre las causas que permiten la extinción del contrato de trabajo de forma objetiva recogidas en el art. 52, c) ET, se contempla una remisión a las causas previstas en el art. 51.1 del mismo, siempre que la extinción afecte a un número inferior de trabajadores al establecido en dicho precepto para los despidos colectivos. Las causas de naturaleza económica, técnica, organizativa y de producción operan en idénticos términos para el despido objetivo y el colectivo, y nos encontraremos en una u otra circunstancia en función del número de trabajadores afectados. Así, la extinción tendrá la consideración de colectiva si el despido afecta, en un período de noventa días, al menos a:

- 10 trabajadores, en empresas que ocupen menos de cien trabajadores.

- $\quad$ El $10 \%$ en aquellas que ocupen entre cien y trescientos trabajadores.

- 30 trabajadores en las empresas que ocupen más de trescientos

Se eliminan de su regulación legal las referencias a la acreditación de proyección de futuro, que resultaba para la empresa de imposible prueba, y que ha venido ocasionando la emisión de juicios de oportunidad relativos a la gestión de la empresa por parte de los tribunales.

REALA, n 1, enero-junio 2014, ISSN: 1989-8975 - DOI: http://dx.doi.org/10.24965/reala.v0i1.10141 
La norma señala que se entenderá que concurre causa económica cuando se produzca una situación de insuficiencia presupuestaria sobrevenida y persistente para la financiación de los servicios públicos correspondientes. En todo caso, se entenderá que la insuficiencia presupuestaria es persistente si se produce durante tres trimestres consecutivos. Se entenderá que concurren causas técnicas, cuando se produzcan cambios, entre otros en el ámbito de los medios o instrumentos de la prestación del servicio público de que se trate y causas organizativas, cuando se produzcan cambios, entre otros, en el ámbito de los sistemas y métodos de trabajo del personal adscrito al servicio público³.

También resulta interesante, frente a la posibilidad de que de forma unilateral por los órganos de gobierno de las entidades públicas se acuerde la inaplicación de los convenios colectivos de personal laboral, analizar las decisiones jurisdiccionales basadas en el art. 32.2 EBEP y la D.A. 20 ET, y hasta qué punto acogen los jueces y tribunales la aplicabilidad de dichos preceptos en las entidades locales frente a la eficacia jurídica y la fuerza vinculante de la que están dotados los convenios colectivos.

\section{CONTROL JUDICIAL DE LOS DESPIDOS COLECTIVOS EN LA ADMINISTRACIÓN}

Debemos recordar que, en nuestro actual ordenamiento, el art. 149.1.7. ${ }^{\text {a CE }}$ atribuye al Estado "competencia exclusiva sobre la legislación laboral, sin perjuicio de su ejecución por los órganos de las Comunidades Autónomas". Ya desde muy temprana fecha, el Tribunal Constitucional (citar, por todas, SSTC 04/05/1982, 30/06/1982 y 27/07/1982) ha interpretado este precepto en el sentido de que el término "legislación laboral" incluye a los reglamentos ejecutivos que complementan o desarrollan la Ley, que, por tanto, son también competencia del Estado, atribuyendo a las respectivas CC.AA. la potestad de dictar reglamentos internos de organización de los servicios correspondientes en materia de su competencia.

En desarrollo de dicha competencia, el gobierno surgido de las elecciones generales de 2011 estimó que la crisis económica había evidenciado la insostenibilidad del modelo laboral español y había puesto de relieve las debilidades de ese modelo, lo que le exigió adoptar una reforma que proporcionara a los operadores económicos y laborales un horizonte de seguridad jurídica y confianza en el que desenvolverse con certeza para conseguir recuperar el empleo. Todo esto conllevó una reforma que trataba de garantizar tanto la flexibilidad de los empresarios en la gestión de los recursos humanos de la empresa como la seguridad de los trabajadores en el empleo y adecuados niveles de protección social. Una reforma que definía como una reforma en la que todos ganan, empresarios y trabajadores, y que pretende satisfacer más y mejor los legítimos intereses de todos4.

Una de las medidas "estrella" de dicha reforma laboral no es otra que la flexibilización del despido en el ámbito de las relaciones laborales, con la acuñación del término "flexiseguridad". No obstante, flexibilizar no tiene por qué ser sinónimo de vuelta a la ley del más fuerte, a la ley de la jungla o, ni mucho menos, al "todo vale" dejando a criterio de los tribunales la valoración sobre la concurrencia de las causas, al haberse suprimido la exigencia de autorización administrativa previa.

\section{La Agencia de Protección de Datos de la Comunidad de Madrid}

La Agencia de Protección de Datos de la Comunidad de Madrid (APDCM) es una entidad de Derecho Público, con personalidad jurídica propia, creada por ley autonómica en 1990, que tenía por objeto velar por el cumplimiento de la legislación en materia de protección de datos.

En fecha 30/11/2012, se lleva a cabo la oportuna comunicación a los representantes legales de los trabajadores, "como inicio del trámite de despido colectivo, con el objeto de llevar a cabo la extinción de 16 contratos de trabajo, totalidad de trabajadores pertenecientes al único centro de trabajo que tiene la citada Agencia en Madrid", procediéndose, en la misma fecha, a entregar memoria explicativa y anexos y comunicándose, de forma simultánea, a la autoridad laboral. Basaba su decisión extintiva en la extinción de la personalidad jurídica de dicha Agencia, conforme al art. 49.1,g) ET5 , aduciendo como razón justificadora el Proyecto de Ley de Medidas Fiscales y Administrativas para 2013 cuyo artículo 55 preveía la extinción de la APDMC.

El 13/12/2012 la APDMC comunica la decisión definitiva (extintiva de la totalidad de los contratos de trabajo) una vez finalizado el periodo de consultas "sin acuerdo" lo que desembocó en la interposición de la oportuna demanda por la representación sindical. La STSJ Madrid n²84/2013 de 25 de marzo considera nulo el despido colectivo puesto que, encontrándonos en un supuesto de extinción de la personalidad jurídica del contratante, que

3 http://portalformacion.lexnova.es/campus-virtual

4 Preámbulo de la Ley 3/2012, de 6 de julio, de medidas urgentes para la reforma del mercado laboral (BOE $n^{\circ} 162$, de 07/07/2012)

5 De acuerdo con este precepto, en los casos de extinción de la personalidad jurídica del contratante, que conlleva la extinción del contrato de trabajo, deberán seguirse los trámites del artículo 51 de esta Ley.

6 Y ello es así porque de acuerdo con el art. 51.2 ET establece que el periodo de consultas tendrá una duración no superior a treinta días naturales, pero en el caso de empresas de menos de cincuenta trabajadores, la duración de este periodo de consultas será no superior de quince.

REALA, n 1, enero-junio 2014, ISSN: 1989-8975 - DOI: http://dx.doi.org/10.24965/reala.v0i1.10141 
debe realizarse conforme a los trámites del art. 51 ET, "la causa en que se basa el despido aquí enjuiciado no existía al tiempo de entregarse las cartas de despido a los trabajadores" (F.J. $9^{\circ}$ ) al estar condicionada la extinción contractual a la aprobación definitiva del Proyecto de Ley de las Medidas Fiscales y Administrativas para 2013 por lo que, para el Tribunal nos hallamos ante un "despido preventivo, vulnerando con ello toda la jurisprudencia de nuestro Tribunal Supremo que exige la existencia de causa al momento de entrega de la comunicación extintiva”. Asimismo apreció la ausencia de un requisito formal (no se hace mención expresa de la causa de la decisión extintiva en la carta de despido) lo que vicia de nulidad dicha comunicación conforme reiterada jurisprudencia que sostiene que la causa no puede ser abstracta (STS 30/10/2010), ya que "la norma sanciona con nulidad el defecto en la precisión de la causa".

Todo lo anterior llevó al Tribunal a establecer respecto de la decisión de despido colectivo que ésta sólo puede producirse por exigencia legal "dado que la causa del despido que consta en la carta refiere una que queda sometida a condición resolutoria, supuesto no contemplado en la legislación laboral, el despido merece calificarse como nulo”.

\section{Telemadrid}

También tuvo ocasión el TSJ Madrid de pronunciarse acerca del procedimiento de despido colectivo instado por en ente público Radio Televisión Madrid, que afectó a casi el 80\% de la plantilla (925 trabajadores sobre un total de 1161 empleados). El periodo de consultas, en el que la representación sindical realizó varias propuestas encaminadas a reducir el número de despidos (hecho probado 13²) finalizó sin acuerdo el 04/01/2013.

La STSJ Madrid n 191/2013 de 9 de abril, esencialmente a los efectos de cumplimiento de los requisitos formales de la D.A. $20^{\mathrm{a}} \mathrm{ET}$, concluye en su F.J. $2^{\circ}$ que Telemadrid no es un Ente público por lo que no se encuentra entre el ámbito subjetivo de la D.A. $20^{\mathrm{a}} \mathrm{ET}$, ya que "Este tipo de entidades no asumen materias que impliquen el ejercicio de lo que se denomina "autoridad pública", por lo que el hecho de que les sean aplicables las normas presupuestarias, contables, de control financiero y contratación, no determina que las mismas constituyan en Administración autonómica", conforme la STSJ Cantabria 708/2012. También concluye la Sala que nos encontramos ante un grupo empresarial a efectos laborales al apreciarse una apariencia externa de unidad empresarial y una unidad de gestión y dirección, además de constituirse en un único ámbito de negociación colectiva (STSJ Madrid 12/04/2012), configurándose como una "única unidad de imputación", entendiendo que no es necesaria, para apreciar grupo empresarial, que concurran todos los requisitos fijados por la jurisprudencia (SSTS 22/01/1990, 30/01/1990, 08/10/1987,...)

Desgajado, pues, el ente Telemadrid del concepto de Administración Pública del art. 3.2 TRLCSP, la Sala postula la aplicación íntegra del art. 4 del RD 1483/2012, considerando en este caso cumplido el requisito de documentación justificativa de la situación económica negativa, dado el carácter tasado de la enumeración el art. 124 LRJS de las causas de nulidad. Por su parte, el F.J. $5^{\circ}$ recuerda que la obligación de negociar con buena fe es una obligación recíproca, por lo que no cabe apreciar mala fe en caso de que no se haya alcanzado acuerdo durante el periodo de negociación, máxime cuando se ha producido en una situación "extremadamente conflictiva". Tampoco la Sala entiende irregular que por la empresa únicamente se aporten los criterios para designar a los trabajadores afectados y no un listado nominativo (ex art. 3.1,e) RD 1483/2012) exigiendo, eso sí, que dichos criterios cumplan con los parámetros de idoneidad y suficiencia, aún cuando se conjuguen criterios objetivos (afectación departamental) con otros subjetivos y personales (capacidad e idoneidad en la gestión), todo ello sin menoscabo del denominado principio de adecuación social7; por todo ello, entiende que la ausencia de ese listado nominativo no supone una ausencia de requisitos formales, dado que se han acreditado los criterios de selección.

No obstante lo anterior, el expediente de despido colectivo es finalmente declarado no ajustado a Derecho por causas fundadas en la causa económica alegada. Efectivamente, la Sala establece que "una situación económica negativa, cualquiera y por sí misma no basta para justificar los despidos de 925 trabajadores de una plantilla total de 1161 [...] la situación económica no puede operar de forma abstracta" (F.J. 13º). Prosigue diciendo que "La justificación del despido económico tiene que realizarse a través de tres pasos: $1^{\circ}$ ) Acreditar la existencia de una situación económica negativa; $2^{\circ}$ ) Establecer el efecto de esa situación económica sobre los contratos de trabajo, en la medida en que aquélla provoca la necesidad de amortización total o parcial de los puestos de trabajo y $3^{\circ}$ ) Mostrar la adecuada proporcionalidad entre las medidas extintivas adoptadas para responder a esa necesidad". Siguiendo este hilo argumental, la sentencia declara probado el requisito de situación económica de pérdidas del grupo y entiende que el segundo requisito es más controvertido, pero que el tercer requisito no se ha podido llegar a probar por la empresa. La sentencia establece que el despido está justificado si se realiza para corregir un desajuste de plantilla, invocando "... la razonabilidad como proporcionalidad, que se convierte en una técnica de ponderación de sacrificios [...] el recurso al despido masivo no está justificado porque la causa no está bien ponderada y el resultado no es razonable a la causa económica alegada", con base en la STSJ Galicia 13/12/2012. La proporcionalidad supone para la

7 Según este principio, las acciones deben guardar una cierta proporcionalidad entre el alcance y la intensidad, por un lado, y los objetivos, por el otro. 
Sala una necesaria correspondencia entre la entidad de la causa económica y el número de extinciones, no siendo suficiente basarlo en una reducción de presupuesto, hecho que resulta "congénito a un servicio público".

\section{Ayuntamiento de Jerez de la Frontera}

La situación económica del Ayuntamiento de Jerez llevó a que, en sesión de la Junta de Gobierno Local de 30/03/2012, se aprobase un Plan de Ajuste acorde al R.D. Ley 4/2012, en el que se contemplaba un ahorro en costes de personal de 13.200.000 € mediante despidos colectivos. Dicho plan, favorablemente informado por el Ministerio de Hacienda, establecía, además, un ahorro de 12.000.000 € por la aplicación de una nueva Relación de Puestos de Trabajo; otros 4.000.000 € mediante la extinción por causas objetivas del contrato de empleados en el resto de entidades dependientes del Ayuntamiento de Jerez; y además 4.000.000 € mediante la modificación sustancial de las condiciones de trabajo de los empleados municipales. Según el Informe de análisis y diagnóstico de la situación económico financiera del Ayuntamiento de Jerez, su plantilla ascendía, en 2010, a 1998 empleados de los que apenas el $31 \%$ eran funcionarios.

Bajo estas premisas, la Junta de Gobierno Local acuerda el 22/06/2012 promover un procedimiento de despido colectivo que afectaría, en principio, a unos 300 trabajadores, comunicándose la decisión a la autoridad laboral y a los representantes de los trabajadores en fecha 19/07/2012. Pese a la finalización sin acuerdo del periodo de consultas se acordó la reducción del número de extinciones de 300 a 273 afectados (cifra que finalmente queda en 260) que son despedidos con efectos 12/09/2012. Ello originó la interposición de la correspondiente demanda de la que conoció la Sala de lo Social del TSJ Andalucía con sede en Sevilla, en los autos acumulados 12/12, 13/12 y 14/12.

En relación con las causas económicas, aducía el Ayuntamiento un remanente negativo de Tesorería de 421.945.011,22 $€$ en el ejercicio 2011, habiéndose incrementado en un 250\%, entre los ejercicios 2010 y el 2011 , los derechos pendientes de cobro y las obligaciones de pago. En cuanto a los criterios de selección de los trabajadores afectados, ésta se hizo en dos fases: en la primera se determinó el número de extinciones por departamentos y categorías profesionales, atendiendo a la necesidad del mantenimiento de la estructura organizativa y funcional del Ayuntamiento. Una vez determinado el número, en la segunda fase, se determinaban concretamente los trabajadores afectados, aplicando dos criterios. El primero, el de la edad, extinguiéndose los contratos de los trabajadores que tuvieran cumplidos 59 años y el segundo criterio, el de la evaluación continua. No obstante, consta como hecho probado en la sentencia que "Para la aplicación de este criterio los responsables de cada delegación, previa consulta con el personal técnico a su cargo, seleccionaron los trabajadores con mayor competencia técnica, formación, experiencia y polivalencia. Y, por exclusión de los anteriores, se seleccionaron a los afectados por el despido colectivo. No obstante, alguno de los seleccionados como con mayor competencia técnica, formación, experiencia y polivalencia, resultó afectado por el despido colectivo".

Sin embargo, en la sentencia se hace mención a las declaraciones de responsables políticos y técnicos que manifestaron que la selección se hacía en función de la información sobre quién trabajaba mejor o peor, era problemático, quejica, y basándose en "rumorología" sobre la actitud ante el trabajo, con base en informes verbales, no valorando la formación y bajo afirmaciones de quiénes no eran no eran buenos trabajadores y eran conflictivos, teniendo en cuenta aquéllos que no hacían nada y el responsable desconocía el currículo. En definitiva, el criterio era sobre quién era vago, mejor o peor, no problemático, sin tener en cuenta la formación, sólo la capacidad sobre el mal desempeño, desconociéndose su polivalencia, con ausencia de informes escritos sin tener en cuenta la formación académica, no existiendo evaluación y dando por buenos “comentarios del servicio",... En otros departamentos se pidió "una relación de personas imprescindibles, la hizo y sin embargo, algunos están en el ERE y otros no" (Hecho Probado $17^{\circ}$ ).

La STSJ Andalucía n 938/13 de 20 de marzo (que comienza por desestimar la cuestión de inconstitucionalidad interpuesta por los sindicatos demandantes) contempla la actuación de la Corporación de acuerdo con la redacción del art. 124.11 LRJS sobre la petición de nulidad de la decisión extintiva, considerando que no ha existido ausencia de negociación (todo ello sin perjuicio de lo establecido en la STSJ Madrid 30/05/2012); que se ha aportado, desde el punto de vista formal, la documental exigida por las normas de aplicación en aquel momento (art 51.2 ET y art. 6 RD 801/2011) sobre la situación económica, así como el listado de criterios para designar a los trabajadores afectados, no apreciándose vulneración de derechos fundamentales y libertades públicas.

Desestimada la nulidad de la decisión extintiva, analiza la Sala si la misma ha sido no ajustada a Derecho. Sentado que “... el Ayuntamiento demandado no es responsable de la actuación de la representación de los trabajadores en orden a la limitación, en su caso, del número de negociadores, ni se aprecia en el Consistorio infracción alguna de las normas sobre constitución de la Comisión negociadora” (F.J. $11^{\circ}$ ), determina la sentencia que en la designación nominal de los trabajadores afectados por la medida extintiva "ha quedado acreditado por la prueba de interrogatorio de testigos practicada en el acto del juicio oral, que en la aplicación de estos criterios se ha incurrido en arbitrariedad, 
lo que adquiere una mayor gravedad dada la condición de Administración Pública de la parte demandada [...] en la aplicación del sistema o criterio de evaluación continua, se ha incurrido en una absoluta arbitrariedad, proscrita por el artículo 9.3 de la Constitución, que contempla la interdicción de la arbitrariedad de los poderes públicos".

La Sala afirma que con el establecimiento de unos parámetros tales como la evaluación continua, competencia técnica, formación, experiencia, polivalencia,... se garantizaría el cumplimiento de los principios de mérito y capacidad, constituyendo un criterio objetivo y razonable. No obstante, esta concreción se hizo “... a juicio subjetivo del técnico o del delegado y, con una valoración personal, subjetiva y arbitraria, carente de la aplicación de cualquier parámetro objetivo, fueron determinados los trabajadores afectados por la decisión extintiva, sin tenerse en cuenta ni su competencia técnica, ni su formación, ni su experiencia, ni la polivalencia. De este modo Ayuntamiento demandado no negoció de buena fe con los representantes de los trabajadores, al facilitarles una lista nominal de trabajadores afectados por la extinción colectiva, sin aplicar los criterios de selección contenidos en el escrito de inicio del procedimiento y en la memoria explicativa".

De este modo, el decisión extintiva de despido colectivo instado por el Ayuntamiento de Jerez (pese a la existencia de negociación, la adopción de medidas reductoras en el número de afectados, la aplicación de criterio objetivo de edad, la adopción de medidas paliativas y el diseño de un plan de recolocación) fue declarado como no ajustado a Derecho por la STSJ Andalucía n 938/13 al no apreciarse buena fe por no aplicarse a la lista nominal de trabajadores afectados los criterios de selección contenidos en el escrito de inicio del procedimiento y en la memoria explicativa. Esa estimación parcial de la demanda conllevó reconocer el derecho de los trabajadores despedidos, a opción del Ayuntamiento, a ser readmitidos en sus puestos de trabajo, con el abono de los salarios dejados de percibir desde la fecha del despido o, a que se les abonase una indemnización de 45 días por año de servicio por el tiempo de prestación de servicios anterior al 12 de febrero de 2012 y a razón de 33 días de salario por año de servicio por el tiempo de prestación de servicios posterior.

\section{Ayuntamiento de Estepona}

Otro Ayuntamiento andaluz con graves problemas económicos era el caso del de Estepona. Este Ayuntamiento presentaba un fuerte desequilibrio presupuestario, la ausencia casi total de autofinanciación y la existencia de una importante deuda extrapresupuestaria, todo ello como consecuencia de obligaciones firmes contraídas por la Corporación Municipal en los últimos años sin consignación presupuestaria, a lo que debía unir la existencia de un determinado número de sociedades mercantiles locales incursas en causa legal de disolución. Ante dicho escenario se habían adoptado diversas actuaciones en orden a buscar soluciones a la situación económica y financiera (modificación de los convenios colectivos vigentes en agosto de 2011, acuerdo de 30/09/2011 de asunción por el Ayuntamiento tanto del personal como de los servicios que prestaban las sociedades mercantiles locales y disolución de éstas, aprobación el 31/10/2011 de Plan de Mejora y Saneamiento Económico,...). No obstante lo anterior, como consecuencia del RD Ley 4/2012 y con el fin de obtener financiación para el pago de las deudas a proveedores, el 30 de marzo de 2012 el Pleno del Ayuntamiento aprobó el Plan de Ajuste Económico en el que, entre otras medidas, acordó imponer límites máximos al coste de personal y disminuir la masa salarial en el año 2012 en 6.000.000 €. Dicho Plan fue informado favorablemente por el Ministerio de Hacienda y fue dado a conocer a los representantes de los trabajadores en Mesa General de Negociación de 24/05/2012.

El 07/06/2012 el Ayuntamiento dirigió oficio al a autoridad laboral por el que comunicaba el inicio de un período de consultas con la representación de los trabajadores del Ayuntamiento con carácter previo a la extinción colectiva de contratos de trabajo, por causas económicas y organizativas, que afectaba a 176 trabajadores. Ese mismo día, le fue entregada a la representación legal de los trabajadores tanto la memoria explicativa como la documental que soportaba la misma. A partir de ese momento se inició el periodo de consultas de treinta días. En ese intervalo, en sesión celebrada el 21/06/2012 el Pleno del Ayuntamiento de Estepona analizó el expediente, las causas económicas y organizativas de la extinción de los contratos de trabajo, la determinación de los criterios empleados, etc... Finalizado el periodo de consultas sin acuerdo, el Ayuntamiento comunicó a la autoridad laboral que las extinciones laborales se harían efectivas entre el 30 de julio y el 31 de agosto de 2012, y que había dado traslado a los trabajadores de la decisión extintiva a la vista del resultado del período de consultas. Los despidos individuales se llevaron efectivamente a cabo por e! Ayuntamiento a partir del 31 de julio de 2012.

En cumplimiento del art. 51 y D.A. $20^{\text {a }}$ ET, la Inspección Provincial de Trabajo y Seguridad Social de Málaga emitió informe en el que se concluía que "El expediente se fundamenta en causas económicas y organizativas. La empresa ha dado cumplimiento a lo dispuesto en el artículo 51.2 del Real Decreto Legislativo 1/95, de 24 de marzo (BOE del 29) en redacción dada por el Real Decreto Ley 3/2012, de 10 de febrero (BOE 11) de acompañar a la comunicación de apertura del período de consultas de una memoria explicativa de las causas del despido colectivo y de los restantes aspectos del artículo $51.1 \mathrm{del}$ mismo texto legal. Asimismo durante el desarrollo del período de consultas se ha trata- 
do sobre la posibilidad de evitar o reducir los despidos mediante la aplicación de medidas alternativas a los mismos así como de atenuar sus consecuencias mediante la aplicación de medidas sociales de acompañamiento. Por todo lo anterior el funcionario que suscribe estima -sin perjuicio de otro superior criterio administrativo o judicial- que se ha observado el procedimiento y que se especifican las causas del despido colectivo, económicas y organizativas, conforme al artículo 51.1 del Real Decreto Legislativo 1/95, de 24 de marzo (BOE del 29) en redacción dada por Real Decreto Ley 3/2012, de 10 de febrero (BOE 11)".

Las organizaciones sindicales interpusieron demandas frente al Ayuntamiento de Estepona, en cuyo suplico interesaban que se dictase sentencia declarando nulo el despido colectivo o, en su caso, no ajustado a Derecho, con derecho de opción a favor de los trabajadores que culminó en la STSJ Andalucía n 1662/12 de 25 de octubre. Postulaban como cuestión de nulidad en supuesta incompetencia funcional del Alcalde para adoptar la decisión del despido, considerando la Sala que "la ley no exige que los despidos de los trabajadores, y en consecuencia los despidos colectivos, del Ayuntamiento sean competencia del Pleno, sino que esa decisión compete al Alcalde, sin perjuicio de que de la misma deba dar cuenta al Pleno, lo que en el caso enjuiciado, se produjo en el Pleno que tuvo lugar el 21 de junio de 2012" (F.J. $3^{\circ}$ ). En cuanto a la alegada vulneración de derechos fundamentales y libertades públicas (el expediente no afectaba a personal funcionario) la Sala recuerda en el F.J. $4^{\circ}$ "la consolidada doctrina del Tribunal Constitucional que para poder apreciar la existencia de discriminación debe partirse del análisis de situaciones jurídicas homogéneas, circunstancia que no concurre en el régimen jurídico del personal laboral y del personal funcionario del Ayuntamiento de Estepona", además de que el expediente de regulación de empleo se encuentra regulado en las Administraciones Públicas en la D.A. $20^{\mathrm{a}}$ ET, aplicable exclusivamente al personal laboral, por lo que no cabe apreciar la nulidad del art. 62.1,a) LRJ-PAC. Tampoco aprecia la nulidad al amparo del art. 62.1,f) LRJ-PAC por la inexistencia de RPT o Plan de Ordenación de Recursos Humanos, puesto que la aplicación del despido colectivo sin la existencia de dichos instrumentos en las Administraciones Públicas no viola "las previsiones contenidas en los artículos 15 y 16 de la Ley 30/1984 (este último derogado por el apartado b) de la Disposición Derogatoria Única de la Ley 7/2007), 26, 27 y 90.2 de la Ley 7/85 y 69, 83, 85 y 88 (estos dos últimos no aplicables al personal laboral) de la Ley 7/2007, de 12 de abril, del Estatuto Básico del Empleado Público". ${ }^{8}$

Por otro lado, apreció la Sala que se había dado cumplimiento a la obligación de hacer entrega a la representación de los trabajadores de la documental exigida tanto en los arts. 51.2 y 51.10 ET como en los arts. 6 y 7.1 RD $801 / 2011^{9}$, en particular, aquélla "que ponía de manifiesto de manera detallada la situación económica y organizativa del Ayuntamiento".

Conforme la STSJ País Vasco 2980/2012 de 11 de diciembre, el período de consultas “... es un verdadero proceso de negociación, guiado por la búsqueda de un acuerdo, con un contenido mínimo obligatorio, en el que ambas partes están obligadas a negociar de buena fe. $\mathrm{Y}$, en modo alguno, constituye un mero requisito de forma para proceder a la realización de los despidos colectivos, por lo que no basta con una actuación de las partes tendente a la simple observancia formal del trámite, sino que es precisa la adopción de una conducta activa y positiva en aras a procurar su cumplimiento real y efectivo, orientada por los valores de probidad, lealtad, honradez, rectitud, corrección, respeto, coherencia, y fidelidad a la palabra dada y al comportamiento seguido". La Sala concluye que se ha producido una real y efectiva negociación en el periodo de consultas, considerando además un "ejercicio de transparencia" el hecho de que "la lista de trabajadores afectados por el expediente de regulación de empleo fuese conocida desde un principio".

No obstante, no sólo basó el Ayuntamiento en causas económicas el expediente de despido colectivo. Respecto de las causas organizativas alegadas, en su el F.J. $12^{\circ}$ la Sala establece que "La aludida Disposición Adicional Vigésima del Estatuto de los Trabajadores, prevé también el despido por causas organizativas, entendiendo que concurren esas causas cuando se produzcan cambios, entre otros, en el ámbito de los sistemas y métodos de trabajo del personal adscrito al servicio público. Esa identificación de las causas organizativas no tiene, pues, carácter cerrado. Y la más evidente causa organizativa justificativa del despido objetivo es el sobredimensionamiento de la plantilla del personal laboral del Ayuntamiento, que trae su causa de la subrogación del Ayuntamiento en el personal laboral de las sociedades municipales disueltas...". También ha tenido directa relación con las medidas extintivas la normativa presupuestaria puesto que la Entidad Local había barajado otras opciones antes de decidirse por el despido colectivo ("El Ayuntamiento había pensado aprobar una Relación de Puestos de Trabajo, de la que carece, y publicar ofertas públicas de empleo para cubrir la totalidad de las plazas de dicha Relación, ofertas a las que podrían presentarse la totalidad de los trabajadores subrogados. Sin embargo, tras la publicación de la Ley de Presupuestos Generales del Es-

8 Y ello no obstante cierto sector de la doctrina que postula la necesidad de tener aprobada una RPT, Plan de Empleo o Plan de Reordenación para proceder a un despido colectivo en el seno de las Administraciones Públicas.

9 El art. 2 de la Orden ESS/487/2012 establecía la vigencia transitoria de determinados artículos del Reglamento aprobado por Real Decreto 801/2011 hasta la entrada en vigor del 1483/2012, por el que se aprueba el Reglamento de los procedimientos de despido colectivo y de suspensión de contratos y reducción de jornada. 
tado para 2012, el Ayuntamiento se vio impedido de hacer ofertas públicas de empleo, con lo que desechó su intención inicial de aprobar una Relación de Puestos de Trabajo, y no fue sino tras la entrada en vigor del Real Decreto Ley 3/2012, cuando procedió al despido colectivo por causas organizativas.")

Todo lo anterior, el cumplimiento de las obligaciones de índole formal y procedimental, llevar a cabo un auténtico periodo de consultas con la representación sindical negociado de buena fe, la acreditación pormenorizada de las causas económicas y organizativas aludidas y la adopción de los acuerdos por los órganos competentes llevaron a la declaración de ajuste a Derecho de la decisión extintiva, declarada por el TSJ de Andalucía.

\section{Los Consorcios de las UTEDLT de la provincia de Málaga}

Los Consorcios de las Unidades Territoriales de Empleo, Desarrollo Local y Tecnológico (UTEDLT) son entidades de derecho público que gozan de personalidad jurídica propia, promovidas y participadas por la Consejería de Economía, Innovación, Ciencia y Empleo de la Junta de Andalucía, a través del Servicio Andaluz de Empleo (SAE) y por EE.LL., que tienen como objeto fomentar la creación de empleo en el ámbito local, conseguir un mayor desarrollo equilibrado y sostenible del territorio, así como lograr un acercamiento de los servicios y de las políticas activas de empleo a la ciudadanía. El personal que atendía dicho Consorcio se regía por la legislación laboral y su coste estaba sufragado por las aportaciones de la Consejería de Empleo y de las Corporaciones Locales, éstas últimas en en un porcentaje variable en función del número de habitantes del municipio ${ }^{10}$.

En 2012 existían en Andalucía un total de 95 Consorcios UTEDLT, de los que un total de 14, que empleaban a 107 trabajadores con relación laboral de carácter indefinido, estaban radicados en la provincia de Málaga. Como es lógico, la concesión de las correspondientes subvenciones se encontraban condicionadas a la existencia de dotación presupuestaria.

Dado que las subvenciones contempladas en el Presupuesto de la Junta de Andalucía para estos Consorcios sufrían una drástica reducción, la Presidenta de dichos organismos envió carta individual a todos los trabajadores en fecha 02/08/2012, comunicando que se iba a iniciar un ERE de despido colectivo a la totalidad de la plantilla como consecuencia del cese total de la actividad, por causas económicas, fijando como fecha de inicio del periodo de consultas el 29/08/2012. Es comunicado en fecha 30/08/2012 a la autoridad laboral el inicio del procedimiento de despido colectivo fundado en causas objetivas prevista en los arts. 52,c) y e) ET, uniendo las oportunas memorias justificativas de la concurrencia de las causas de extinción de 11 de ellos, de acuerdo con el Informe de insuficiencia presupuestaria para el mantenimiento de la financiación de los costes de personal de los consorcios UTEDLT en Andalucía, emitido por el SAE en fecha 08/08/2012, así como el listado de los trabajadores afectados. El periodo de consultas finalizó el 25/09/2012, sin acuerdo. El 27 del mismo mes es comunicado individualmente a los trabajadores afectados la extinción de sus contratos con efectos 30/09/2013".

Por el Comité de empresa provincial se promueve la oportuna demanda contra los Consorcios, el SAE, los Ayuntamientos consorciados y la Consejería competente de la Junta de Andalucía, que desemboca en la STSJ Andalucía (Málaga) n³92/2013 de 27 de febrero. Alternativamente, solicita el demandante la subrogación de sus contratos por la Junta de Andalucía, a través del mecanismo del art. 44 ET. Tras desestimar la posibilidad de que se Ilevase a cabo la subrogación solicitada, la Sala entra al fondo del asunto para dejar patente en el F.J. $7^{\circ}$ la importancia tanto de los requisitos de forma como de fondo así como aclarar el papel de juzgador en el actual escenario: "la procedencia del despido colectivo exige una regularidad formal consistente en que se sigan los procedimientos para ello establecidos y que se cumplan los requisitos y trámites exigidos y de no cumplirse tales requisitos la modificación es nula, y además un regularidad material consistente en que existan las razones materiales que justifican la modificación y además que aparezcan probadas; la vía judicial no es un cauce para corroborar y confirmar simplemente la actuación empresarial por sí sola, sino para determinar si esta actuación se adapta y cumple los requisitos de forma y de fondo establecidos legalmente, debiendo la empresa demostrar el cumplimiento de los requisitos de forma so pena de nulidad y de fondo determinantes de su decisión modificadora".

La Sala, en cuanto a tales requisitos formales, y basándose en la STS 10/06/2007, establece que las causas generadoras del despido colectivo deben ser objeto de análisis, examen y tratamiento en el periodo de consultas. Asimismo, en cuanto a una situación de iliquidez que impidió la puesta a disposición inmediata de las indemnizaciones (solucionado tras los oportunos trámites administrativos) reitera los fundamentos de la STSJ Andalucía 359/2013 al establecer que no debe ser objeto de impugnación de despido colectivo el incumplimiento en la comu-

10 El SAE sufragaba el 100\% de los gastos de la estructura básica y los Ayuntamientos un porcentaje del 20\%, 25\% o $30 \%$ de la estructura complementaria, en función de la población de cada municipio, (art. 32,b) de los Estatutos).

11 Por motivos de cercanía nos ceñimos al proceso de la provincia de Málaga, aún cuando con anterioridad recayó la STSJ Andalucía (Granada) n 359/2013, de 12/02/2013, con el mismo objeto pero referido a la provincia nazarí. 
nicación individual del requisito del art. 53.1,b) $\mathrm{ET}^{12}$, dejando dicha cuestión a las correspondientes reclamaciones individuales.

Parte la Sala, en su F.J. $3^{\circ}$, del principio de que la insuficiencia presupuestaria sobrevenida de los Consorcios constituyen causa justificadora prevista en el art. 52,e) y la D.A. $20^{\text {a }}$ ET. En cuanto a los requisitos formales, llega a la conclusión de que quedaron suficientemente cumplidas tanto la celebración del periodo de consultas como la exigencia de aportar "la documentación suficiente de la memoria explicativa, que se han cumplido debidamente los plazos, que no se ha faltado al deber de negociar de buena fe con vistas a la consecución de un acuerdo que impone el artículo 51.2 párrafo octavo, que se ha tratado de minimizar los efectos del despido colectivo, y todo ello dada la naturaleza del empleador y la objetiva y constatada insuficiencia presupuestaria sobrevenida", (F.J. $7^{\circ}$ ) por lo que no puede acoger las alegaciones de la parte demandante en este sentido. Así pues, no aprecia la Sala intención fraudulenta sino que se atiende "a una situación real producida por la constatada insuficiencia presupuestaria sobrevenida" y observa que se ha dado cumplimiento los requisitos formales exigidos por la norma.

Los demandantes adujeron que por los Consorcios, en su calidad de entidades de derecho público, se había infringido el principio de los actos propios y apreciaban fraude de ley en su actividad. La Sala concluye que, siendo aplicable el principio de los actos propios en defecto de norma, dado su carácter de principio general del Derecho ex art. 1.4 CC, debe estarse a la norma sustantiva de aplicación, recordando la STS 16/05/1988 donde se establece la prevalencia del principio de legalidad sobre el de los actos propios en defensa del interés público “... pues sin esta limitación se habría introducido en las relaciones del derecho público administrativo el principio de autonomía de la voluntad en la reclamación de materias reguladas por normas de naturaleza imperativa". Asimismo, en cuanto al fraude de ley recuerda en su F.J. $15^{\circ}$ "la obligación de la parte que alega el fraude, probar el ilícito proceder de la Administración".

Por último, al analizar la pretendida subrogación por el SAE en los contratos de trabajo de los trabajadores afectados, la Sala afirma que "no cabe entender que existe sucesión de empresas, pues lo ocurrido en el caso que se analiza ha sido lo contrario, es decir ante la insuficiencia presupuestaria sobrevenida lo que ha hecho el Servicio Andaluz de Empleo es retirarse de los consorcios, dejar de realizar la actividad que hasta entonces había realizado en los mismos, dejar de contribuir y de realizar las aportaciones a los Consorcios, en consecuencia no ha habido ni transmisión subjetiva ni objetiva ni las notas configuradoras de la sucesión de empresas, ni sucesión en la actividad ni en la plantilla, sino sólo un apartamiento de su participación en los Consorcios motivada por la causa económica indicada y por ende no hay sucesión de empresas". (F.J. 16²)

En definitiva, a juicio de la Sala, acreditada la concurrencia de la "causa habilitante y justificadora" para el despido colectivo por la probada y acreditada situación de insuficiencia presupuestaria sobrevenida y persistente, se dan los requisitos exigidos en el art. 52.6 y D.A. 20 $0^{\text {a }}$, una vez comprobado el cumplimiento de los presupuestos formales, y entiende que la decisión extintiva se "acomoda al ordenamiento jurídico" al concurrir los requisitos legales exigidos, produciéndose con arreglo a las normas reguladoras y cumple los requisitos establecidos, por lo que declara procedente el despido colectivo y ajustadas a derecho las decisiones extintivas.

\section{Diputación de Ourense}

Por su parte, la Diputación de Ourense abordó el 04/12/2012 el despido colectivo de 32 empleados laborales indefinidos por causas económicas. Previamente había llevado a cabo el cese trabajadores temporales y en octubre de 2012, había extinguido los contratos de 30 interinos. El periodo de consultas se extendió desde el 11/12/2012 hasta el 06/02/2013 puesto que, a petición de la parte social, se acordó por unanimidad interrumpir las negociaciones durante el periodo navideño, celebrándose un total de nueve reuniones, que acabaron sin acuerdo. Durante el mismo, el número de despidos se redujo a 28 por diversas razones.

Producidos los despidos, se interpone la demanda por los representantes de los trabajadores y es celebrada vista en el TSJ Galicia, órgano que dicta sentencia en fecha 02/05/2013. Del relato de la misma queda sentada la necesaria aplicación a este tipo de expedientes del Título III RD 1483/2012.

Frente a los criterios seguidos por la Diputación para la selección de los empleados afectados por la decisión extintiva (únicamente personal laboral indefinido no fijo, excluyendo a quienes ostentaban la condición de representante de los trabajadores; aquéllos con un grado de discapacidad reconocido igual o superior al 33\%;

12 Uno de los requisitos del despido por causas objetivas es el de “1. Poner a disposición del trabajador, simultáneamente a la entrega de la comunicación escrita, la indemnización de veinte días por año de servicio, prorrateándose por meses los períodos de tiempo inferiores a un año y con un máximo de doce mensualidades. 2. Cuando la decisión extintiva se fundare en el artículo 52 c), de esta Ley, con alegación de causa económica, y como consecuencia de tal situación económica no se pudiera poner a disposición del trabajador la indemnización a que se refiere el párrafo anterior, el empresario, haciéndolo constar en la comunicación escrita, podrá dejar de hacerlo, sin perjuicio del derecho del trabajador de exigir de aquél su abono cuando tenga efectividad la decisión extintiva". 
ocupantes de puestos de trabajo que resultan imprescindibles; y personal cuyo despido resultaría antieconómico por estar próxima su jubilación) la representación sindical alega una vulneración de derechos fundamentales en su concreción. Sin embargo, la Sala no acoge este motivo, al entender que la determinación de las personas afectadas por despidos de tipo económico, organizativo, técnico, y productivo de los arts. 51 y 52 c) ET, es, "ab initio", competencia única de la empresa, invocando doctrina unificada consolidada (SSTS 19/01/1998 y 19/10/2003) que atribuye la elección de los trabajadores afectados por la medida extintiva de forma exclusiva al empleador, solamente revisable judicialmente en aquellos supuestos en los que exista fraude de ley, abuso de derecho o un móvil discriminatorio. A mayores, una vez determinado por la Sala que aparecía justificada la decisión adoptada por el Organismo demandado, pues todos los trabajadores seleccionados lo fueron al margen de todo móvil contrario a cualquier Derecho Fundamental, no observándose ningún elemento discriminatorio, ni prueba de fraude de ley o abuso de derecho (F.J. $3^{\circ}$ ) recuerda que "es necesario indicar que en la presente resolución, no pueden abordarse cuestiones relativas al posible incumplimiento empresarial de las reglas de prioridad de permanencia previstas legal o convencionalmente, o establecidas en el acuerdo adoptado en el período de consultas, pues dichas pretensiones deben plantearse a través del procedimiento individual que regula el apartado 11 del art. 124 LRJS, conforme dispone el apartado segundo del mismo artículo" así como que en los supuestos en los que se alegue una vulneración de derechos fundamentales o libertades públicas, “... corresponde a la parte que lo alega, la aportación de indicios razonables que fundamenten tal alegato, es decir, deberá desarrollar una actividad probatoria que permita al juzgador deducir la posibilidad de que la lesión se haya producido, no siendo suficiente con alegar la vulneración del derecho fundamental". Tampoco aprecia fraude de ley en la decisión extintiva de la Diputación puesto que se ha evidenciado que no se ha seleccionado al personal incluido en la decisión extintiva de forma aleatoria, sino siguiendo unos "criterios razonables y suficientemente justificados para incluir y excluir a determinados trabajadores, negociando a tal efecto -de buena fe- durante el periodo de consultas".

Por su parte, la representación sindical solicitó la calificación de nulidad del despido colectivo puesto que, a su juicio:
a) EI ERE no afecte al número mínimo de trabajadores exigido por la ley
b) Se había superado con mucho el límite máximo del periodo de consultas
c) No había dispuesto la representación de los trabajadores de toda la documentación necesaria

En el primer caso, la Sala entiende que el hecho de que el número de afectados se redujese en 4 con motivo del periodo de consultas (pasando de 32 a 28) no vicia de nulidad la decisión puesto que, si bien al finalizar el periodo de consultas no se alcanza el umbral fijado por el art. 51 ET y 35.1,c) RD 1483/2012, los umbrales mínimos exigidos por el citado artículo concurrían al inicio del expediente, que es cuando hay que determinar el concreto número de trabajadores afectados a los efectos de acudir o no al procedimiento de despido colectivo.

En cuanto a la alegación de haber superado la duración máxima establecida para el periodo de consultas, lo que supone (a juicio de la representación sindical) "cerrarse dicho ERE al haber caducado", la Sala entiende que va contra los propios actos de la representación de los trabajadores, y es contraria a las reglas de la buena fe dado que fue adoptado a propuesta de la parte social, por unanimidad, y en el seno de la propia Comisión Negociadora. Así, continua la Sala en el F.J. $6^{\circ}$ dice que "Ciertamente el art. 7.5 del Reglamento (RD 1483/2012), dispone que en las empresas de cincuenta o más trabajadores, el período de consultas tendrá una duración no superior a treinta días naturales. Salvo pacto en contrario, conforme a lo establecido en el apartado 2, se deberán celebrar durante el mismo, al menos, tres reuniones, separadas por un intervalo no superior a nueve días naturales ni inferior a cuatro días naturales. Según la dicción literal de la norma, la expresión referida al plazo de duración del periodo de consultas no puede entenderse como "un límite infranqueable", significando dicha expresión que únicamente, superado dicho plazo, que es el que el legislador considera suficiente para que las partes alcancen acuerdos, "ninguna de las partes puede compeler a la otra para prolongar la negociación”. Ahora bien, cuando se considera necesario, por acuerdo entre ambas partes, que la negociación siga abierta, impedir que llegue a buen puerto cuando sea necesario un periodo más prolongado de consultas, quebraría la finalidad esencial del periodo de consultas" (STSJ Cataluña 25/10/2012).

Respecto de la ausencia de documentación necesaria, la Sala se remite al RD 1483/2012, que establece la documentación a aportar por las Administraciones Públicas en caso de despido colectivo fundado en causas económicas, entendiendo que no cabe imponer a la parte (Administración Local) "una exigencia de documentación que exceda de la enumerada en el artículo 39 del Reglamento, para los despidos colectivos por causas económicas, tal como pretende la parte demandante."

Una vez desestimadas las causas de nulidad invocadas ex art. 124.11 LRJS, aborda la sentencia el análisis de la concurrencia de la causa económica, además de valorar las alegaciones efectuadas por la representación sindical en orden a que se procediese por la Diputación a la contratación de nuevos trabajadores durante la tramitación del ERE así como a dos asesores, mientras se aducen problemas de tesorería para pagar los sueldos. 
Con base en el art. 35.3 del Reglamento, la Sala concluye que "es claro que no concurre en la situación económica del Ente Provincial demandado una situación de déficit presupuestario, dado el saldo positivo de sus cuentas. Cierto es que, según testimonio de la Interventora en el importe del remanente se incluyen derechos pendientes de cobro, que no se sabe muy bien si se van a cobrar o no, y que sería precisa su " depuración" contable, por las dudas que genera su realización. Sin embargo, mientras esa "depuración " no se produzca no pueden excluirse de la contabilidad porque se trata de derechos cuya titularidad corresponde al Organismo demandado, y es su obligación el intento de cobranza de los mismos. Por otro lado, y teniendo en cuenta lo dispuesto en el art. 35.3, para que se produzca insuficiencia presupuestaria, es preciso que concurran conjuntamente las situaciones a que aluden los apartados a) y b) de dicha norma, esto es, que en el ejercicio anterior la Administración Pública haya presentado una situación de déficit presupuestario, y que los créditos o las transferencias, se hayan minorado en un 5 por ciento en el ejercicio corriente o en un 7 por ciento en los dos ejercicios anteriores".

Basándose en la STSJ Madrid 09/04/2013 (ERE Telemadrid) "la justificación del despido económico tiene que realizarse a través de tres pasos: $1^{\circ}$ ) Acreditar la existencia de una situación económica negativa; $2^{\circ}$ ) Establecer el efecto de esa situación sobre los contratos de trabajo, en la medida en que aquélla provoca la necesidad de amortización total o parcial de los puestos de trabajo y $3^{\circ}$ ) Mostrar la adecuada proporcionalidad de las medidas extintivas adoptadas para responder a esa necesidad", la Sala concluye que siendo ciertas las minoraciones de los ingresos de la Diputación, "no ha quedado debidamente acreditada una situación económica negativa de insuficiencia presupuestaria, o situación de déficit presupuestario en los términos exigidos por el art. 35.3 del RD 1483/2012” así como que, no observándose déficit presupuestario, no cree que la medida adecuada sea la amortización de la totalidad de los puestos de laborales indefinidos, dado que "sólo sería procedente la extinción de todos los contratos de trabajo, si el desajuste de la plantilla fuese el factor desencadenante de una situación económica negativa, pero no lo es, y es posible, además, que con la adopción de otras medidas, como la reducción de las partidas presupuestarias asignadas al Baloncesto o al Fútbol".

Por último, entiende que "la medida extintiva no puede considerarse de adecuada proporcionalidad para superar una situación económica negativa, pues resulta contraria al deber de buena fe, desde el momento en que simultáneamente a la tramitación de un ERE que comportó la extinción de 25 contratos de trabajo, se nombran dos asesores de confianza con un gasto anual aproximados de 120.000 euros".

De este modo, la STSJ Galicia 02/05/2013 declara no ajustada a Derecho la decisión extintiva de la Diputación de Ourense al no haberse acreditado la concurrencia de una situación de insuficiencia presupuestaria en los términos exigidos por el art. 35 del Reglamento.

\section{La suspensión de aplicación de convenios colectivos}

Es conocido en el ámbito del Derecho del Trabajo la denominada "cláusula de descuelgue", regulada en el art. 82.3 ET por la que, previo reconocimiento de la fuerza vinculante de la negociación colectiva, se posibilita, cuando concurran causas económicas, técnicas, organizativas o de producción, que por acuerdo entre la empresa y los representantes de los trabajadores se pueda proceder, previo desarrollo de un periodo de consultas, a no aplicar determinadas materias del convenio colectivo, entre las que se encuentran las denominadas condiciones sustanciales de las condiciones de trabajo ${ }^{13}$. En el ámbito del empleo público se obviaba el requisito del previo periodo de consultas en virtud del art. 38.10 EBEP, sustituyéndose por un deber de información sobre las causas a las organizaciones sindicales, cuando ese descuelgue se debía a causa grave de interés público derivada de una alteración sustancial de las circunstancias económicas, en la medida estrictamente necesaria para salvaguardar el interés público, si bien se entendía por la jurisprudencia que ésta sólo era de aplicación al personal funcionario. Pues bien, la reforma laboral, a través de la D.A. $2^{\text {a }}$ R.D. Ley 20/2012, ha concretado el alcance de dicho precepto: “A los efectos de lo previsto en el artículo 32 y 38.10 del Estatuto Básico del Empleado Público se entenderá, entre otras, que concurre causa grave de interés público derivada de la alteración sustancial de las circunstancias económicas cuando las Administraciones Públicas deban adoptar medidas o planes de ajuste, de reequilibrio de las cuentas públicas o de carácter económico financiero para asegurar la estabilidad presupuestaria o la corrección del déficit público".

Con la redacción dada al art. 38.10 EBEP, no existían dudas (aparentemente) acerca de su aplicación al personal funcionario y a los acuerdos mixtos, pero no así al personal laboral. Sin embargo, una vez en vigor la reforma laboral y la nueva redacción dada al art. 32 EBEP, acuerdos de entidades públicas tendentes a no aplicar determinados preceptos de convenios colectivos y/o acuerdos de personal laboral están siendo favorablemente acogidas por los órganos jurisdiccionales.

13 Tendrán la consideración de modificaciones sustanciales de las condiciones de trabajo, entre otras, las que afecten a las siguientes materias: Jornada de trabajo; Horario y distribución del tiempo de trabajo; Régimen de trabajo a turnos; Sistemas de remuneración y cuantía salarial; Sistema de trabajo y rendimiento; Funciones, cuando excedan de los límites que para la movilidad funcional. 


\section{Criterios jurisdiccionales antes de la reforma laboral}

Antes de la promulgación de la reforma laboral y amparado en una situación económica negativa, el Pleno del Ayuntamiento de Manresa en fecha 21/06/2010 acordó dejar en suspenso el cumplimiento del art. 48 del convenio colectivo de su personal laboral por el que se comprometía a dotar anualmente una partida presupuestaria destinada a atender prestaciones de odontología, oftalmología, ortopedia, intervenciones de miopía, audífonos, estudios, renovación de los carnés de conducir,... Ello conllevó que por los representantes sindicales se interpusiera demanda de conflicto colectivo que fue desestimada en primera instancia. Recurrida en suplicación, el TSJ Cataluña tuvo oportunidad de pronunciarse sobre la misma en su sentencia $n^{\circ} 7222 / 2011$, de 11 de noviembre. La misma (dictada con anterioridad a la reforma laboral) dejó sin efecto la sentencia de instancia, estimando el recurso de suplicación al entender en su F.J. $3^{\circ}$ que "carece de amparo legal la decisión municipal de suspender la aplicación del artículo 48 del convenio colectivo, debiendo ser a través de los mecanismos previstos en el convenio y mediante la negociación con la parte social donde el Ayuntamiento demandado pueda obtener la modificación del citado precepto convencional". Previamente, había recordado la STC 205/1987 ("en cuanto parte de las relaciones laborales privadas, la Administración está sujeta a las mismas regias jurídicas que las demás empleadoras”) o las SSTS 18/03/1991, 07/10/1992 y 07/10/2004 ("cuando las Administraciones Públicas actúan como empresarios y celebran contratos de trabajo deben atenerse a la normativa general y sectorial que regula la contratación en el Derecho del Trabajo"). También, deja sentado que la aplicación del art. 38.10 EBEP no resultaba de aplicación al personal laboral al servicio de las Administraciones y que, en todo caso, era una posibilidad aplicable a "acuerdos mixtos" en su calidad de acuerdos o pactos para los funcionarios públicos, siguiendo la STS 28/09/2011.

Efectivamente, dicha resolución resolvía recurso de casación interpuesto por el Principado de Asturias. En este caso, el órgano de gobierno del Principado había resuelto eliminar fondos de acción social destinado a sus empleados, contemplado en el art. 59 del Convenio colectivo para el Personal Laboral de la Administración del Principado de Asturias. Contra dicho acuerdo se había alzado la representación sindical, obteniendo la estimación de la demanda por STSJ Asturias 23/12/2010. En este caso, entendió el TSJ que la fuerza normativa de los Convenios Colectivos tiene sanción constitucional y reconocimiento legal, sin que el precepto pueda ser dejado sin efecto por el Acuerdo del Consejo de Gobierno del Principado de Asturias. La STS 28/09/2011 considera que dicha cláusula se encontraba entre las en las que se incluyen las normas de relación que tienen por objeto definir las condiciones de trabajo, la acción asistencial o el ejercicio de los derechos colectivos y las reglas que definen los ámbitos del Convenio (STS 16/06/1998).

Afirma la sentencia que, pese a enmarcarse dentro de un paquete de medidas urgentes de contención del gasto, "el apartado 10 del artículo 38 del EBEP no ampara la desvinculación de lo pactado en un Convenio Colectivo suscrito por la Administración y su personal laboral” (F.J. $4^{\circ}$ ); posteriormente, plasma que aún cuando se plantease su aplicabilidad a efectos "meramente dialécticos", igualmente procedería la desestimación del recurso "dados los términos de excepcionalidad en que está redactado el precepto, la concurrencia del requisito exigible "causa grave de interés público" y la necesidad de la suspensión o modificación para "salvaguardar el interés público" deberían ser debidamente alegados y justificados, aportando, incluso, los informes y datos que sirvan de acreditación, lo que aquí no se ha producido".

Por otro lado, la STSJ Castilla-La Mancha $\mathrm{n}^{\circ}$ 252/2012, de 21 de marzo, resolviendo recurso contencioso-administrativo interpuesto frente a acuerdo del Gobierno de la Junta de Comunidades de Castilla-La Mancha de 13/10/2011, por el que se adoptaban medidas para la reducción del déficit público que implicaron la suspensión de la aplicación de los pactos y acuerdos suscritos por la Administración de la Junta de Comunidades de Castilla La Mancha y las organizaciones sindicales relativos a la derechos sindicales en el ámbito del empleo público autonómico, y recordaba la SAN 13/07/2011 que establecía que "El Tribunal Constitucional ha señalado, en sus sentencias 80/2000 (RTC 2000, 80) y 85/2001 (RTC 2001, 85), que por las peculiaridades del derecho de sindicación de los funcionarios públicos a que se refiere el artículo 28.1CE, no deriva del mismo el derecho la negociación colectiva, si bien en la medida en que una ley, en este caso, la ley 7/2007, de 12 de abril del Estatuto Básico del Empleado Público (EBEP), reconoce el derecho a la negociación colectiva en este ámbito, se integra tal derecho en el de libertad sindical, con la configuración que resulte de la ley reguladora, admitiendo además el TC que en este ámbito de la ley ordinaria pueden establecerse diferencias entre la negociación colectiva en el ámbito laboral y en el ámbito funcionarial", lo que le llevaba a afirmar en su F.J. $2^{\circ}$ que el derecho a la negociación colectiva, al tratarse de un derecho esencialmente de configuración legal implica, entre otras cosas, que los funcionarios y los Sindicatos titulares del mismo, así como las Administraciones públicas en las que éste se desarrolla, no son libres para ejercerlo de modo incondicionado, por lo que "El artículo 33.1 [del EBEP] sujeta la negociación colectiva de las condiciones de trabajo de los funcionarios públicos, entre otros, a los principios de legalidad y cobertura presupuestaria, lo que supone que lo acordado en la negociación en materia de retribuciones está condicionado a lo que dispongan las normas legales aprobadas por el órgano legislativo". 
Posteriormente, haciendo una exégesis del art. 38.10 EBEP afirma la posibilidad excepcional de que la Administración se desvincule unilateralmente de lo pactado (aplicando al campo de la negociación colectiva en el sector público la cláusula rebus sic stantibus), “... que permite a la Administración, excepcionalmente, la revisión, suspensión o modificación unilateral de las obligaciones pactadas en la negociación colectiva, por alteración sustancial de las circunstancias económicas existentes en el momento de la conclusión del pacto o acuerdo", teniendo apoyo legal la desvinculación unilateral de lo pactado si se justifica en una "causa grave de interés público derivada de una alteración sustancial de las circunstancias económicas", aún cuando no es cualquier razón grave de interés público la que justifica la desvinculación sino exclusivamente la de carácter económico. En ese caso, el TSJ entendía que quedaba justificada en la norma "dada la crisis económica que sufre la economía castellano manchega, la grave situación financiera en la que se encuentra la Administración de la Comunidad Autónoma de Castilla La Mancha y la consecuente necesidad de racionalizar los recursos públicos, en particular los destinados al empleo público".

Finalmente, acaba afirmando que, al no imponerse la negociación previa del acuerdo, se habían respetado las exigencias básicas fijadas en el EBEP, es decir, concurrencia de una causa grave de interés público originada por la alteración sustancial de las circunstancias económicas que presidieron la firma del Acuerdo e información previa a las organizaciones sindicales de las causas determinantes de la suspensión o modificación, puesto que "No puede hablarse de violación del derecho a la negociación colectiva pues es la propia Ley la que autoriza el ejercicio de la facultad excepcional de suspensión o modificación de los pactos y acuerdos. Por tanto, la Administración ha actuado conforme a la previsión legal contenida en los preceptos citados, ya que concurren circunstancias económicas imprevisibles y sobrevenidas que justifican la suspensión parcial de la aplicación de las cláusulas de los Acuerdos reseñados, por razones de interés público". (F.J. $3^{\circ}$ )

\section{Sentencias recaídas con posterioridad a la reforma laboral}

En general, la gravedad de la crisis económica y sus consecuencias, así como el cambio radical de la situación económica en relación a la existente cuando se concertaron los convenios colectivos de numerosos Ayuntamientos, han obligado a los gobiernos locales a afrontar y buscar soluciones expeditivas para reducir el déficit público, pues debido a la falta de ingresos ya no es posible afrontar ni soportar los gastos a los que éstos se obligaron en tiempos de bonanza económica. Y han encontrado apoyo para ello en la redacción dada por el art. 7 R.D. Ley 20/2012 al art. 32 EBEP $^{14}$.

Esta situación de urgente necesidad legitima la adopción de medidas extraordinarias puesto que 'lo que aquí debe importar no es tanto la causa de las circunstancias que justifican la legislación de urgencia cuanto el hecho de que tales circunstancias efectivamente concurran" (SSTC 11/2002 y 68/2007) así como la posibilidad de alterar el contenido de los convenios colectivos ante dicha situación sobrevenida puesto que "... del art. 37.1 CE no emana ni deriva la supuesta intangibilidad o inalterabilidad del convenio colectivo frente a la norma legal, incluso aunque se trate de una norma sobrevenida" puesto que "en virtud del principio de jerarquía normativa, es el convenio colectivo el que debe respetar y someterse no sólo a la ley formal, sino, más genéricamente, a las normas de mayor rango jerárquico y no al contrario". (STS 12/04/2012, citando ATC 115/2011). De este modo, como pone de manifiesto la STSJ Baleares 554/2012, de 24 de julio, "El ordenamiento jurídico se dota de instrumentos que permiten suspender la efectividad de un Acuerdo que no resulta económicamente sostenible".

En este sentido, y con apoyo en los ya citados art. 32.2 EBEP y la D.A. $2^{\text {a }}$ RD Ley 20/2012, el Ayuntamiento de Vélez-Málaga acordó, mediante acuerdos de la Junta de Gobierno Local de 1 de octubre y 5 de noviembre de 2012, suspender la eficacia de determinadas cláusulas del convenio colectivo de su personal laboral, quedando supeditada su vigencia a la subsistencia de la difícil coyuntura económica actual y que afecta a la sostenibilidad de las cuentas públicas, circunstancias originadas por el obligado cumplimiento de la Ley Orgánica 2/2012, de Estabilidad Presupuestaria y Sostenibilidad Financiera y con base en el Plan de Ajuste aprobado en fecha 30/03/2012, dando posteriormente cuenta de dichos acuerdos en Mesa General de Negociación.

La representación sindical presentó demanda solicitando que se declarasen nulas o subsidiariamente injustificadas dichas medidas tanto por una vulneración del derecho de negociación colectiva como por no observarse la concurrencia de la excepcionalidad alegada por la Corporación.

La sentencia $n^{\circ}$ 170/2013 del Juzgado de lo Social $n^{\circ} 5$, de Málaga, de 07/05/2013 desestimó las pretensiones de las secciones sindicales, razonando el juzgador de instancia que la norma habilita a los órganos de gobierno de las

14 Art. 32.2 EBEP: Se garantiza el cumplimiento de los convenios colectivos y acuerdos que afecten al personal laboral, salvo cuando excepcionalmente y por causa grave de interés público derivada de una alteración sustancial de las circunstancias económicas, los órganos de gobierno de las Administraciones Públicas suspendan o modifiquen el cumplimiento de Convenios Colectivos o acuerdos ya firmados en la medida estrictamente necesaria para salvaguardar el interés público. En este supuesto, las Administraciones Públicas deberán informar a las Organizaciones Sindicales de las causas de la suspensión o modificación. 
Administraciones Públicas a suspender la eficacia de los pactos y acuerdos de forma excepcional y por causa grave de interés público derivada de una alteración sustancial de las condiciones económicas y, si se justifican dichas circunstancias (en este caso, originadas en el Plan de Ajuste que tuvo que hacer el Ayuntamiento para cumplimiento del RD Ley 4/2012, de pago a proveedores, basado en el informe del Interventor de la Corporación), la suspensión de los acuerdos, "no supone vulneración del derecho a la libertad sindical en su vertiente del derecho a la negociación colectiva", habiéndose cumplido con el requisito del deber de informar a las organizaciones sindicales, al existir "causa para suspender esas normas con clara repercusión económica". ${ }^{15}$

\section{CONCLUSIONES}

A la vista de las distintas sentencias analizadas se puede concluir que los órganos jurisdiccionales del orden social vienen exigiendo en la aplicación de la reforma laboral en las Administraciones Públicas (en especial, en materia de despidos colectivos e inaplicación de cláusulas de los convenios colectivos) los siguientes requisitos:

- Acreditación pormenorizada de las causas que dan origen a la decisión

- Interpretación estricta del concepto de Administración Pública para la aplicación de la D.A. 20ªT

- Exigencia de criterios idóneos y suficientes para la inclusión de trabajadores en la decisión extintiva, proscribiendo la arbitrariedad en la determinación de los afectados, con especial énfasis en que no se incurra en arbitrariedad en la selección de los trabajadores, dado el carácter de Administración Pública que ostenta el empleador

- Razonabilidad y proporcionalidad entre las causas alegadas y las medidas propuestas

- Cumplimiento de las obligaciones de índole formal y procedimental, con estricta observancia de los requisitos formales

- La existencia de una real y efectiva negociación exige que las causas generadoras del despido colectivo deban ser objeto de examen, análisis y tratamiento en el periodo de consultas

- Al amparo del nuevo art. 32.2 EBEP, resulta posible la suspensión unilateral por los órganos de dirección de las Administraciones Públicas de determinadas cláusulas de los convenios colectivos, si bien de forma motivada y excepcional.

\footnotetext{
15 Resulta muy didáctico, a este respecto, el último párrafo del F.D. $5^{\circ}$ SAN 76/2013, de 19 de abril.
} 
